\title{
Non-standard biological activities of lipopolysaccharide from Helicobacter pylori
}

\author{
NAOHIRO MATSUYAMA, TERUO KIRIKAE*, FUMIKO KIRIKAE*, MASAHITO HASHIMOTO*, \\ KEN-ICHI AMANO†, SHUNJI HAYASHI\$, YOSHIKAZU HIRAI\$, TATSUYA KUBOTA§ and \\ MASAYASU NAKANO:
}

Shiraoka Chuo Sogo Hospital, Shiraoka, Saitama 329-0217, *Department of Infectious Diseases and Tropical Medicine, Research Institute International Medical Center of Japan, Shinjuku, Tokyo 162-8655, †Central Research Laboratory, Akita University School of Medicine, Akita 010-8543, \$Department of Microbiology and \$Department of Intensive and Critical Care Medicine, Jichi Medical School, minamikawachi-machi, Tochigi 329-0498, Japan

\begin{abstract}
As assessed by the lipopolysaccharide (LPS)-specific chromogenic Limulus amoebocyte lysate (LAL) assay, Helicobacter pylori LPS extracted by the phenol-water procedure showed full potency to coagulate LAL, as did LPS from Salmonella minnesota and Escherichia coli. However, pretreatment of $H$. pylori LPS with polymyxin B, which easily destroys the endotoxic activity of enterobacterial LPS/lipid A, had little effect on the LAL coagulation activity, although the same treatment of $E$. coli LPS markedly diminished its activity. The $H$. pylori LPS induced very weak production of nitric oxide (NO) or tumour necrosis factor (TNF) by murine macrophages and TNF by human peripheral whole blood in vitro in comparison with $S$. minnesota LPS. These findings indicate that $H$. pylori LPS has the unique endotoxic characteristic of retaining full LAL coagulation activity with polymyxin $B$ resistance, despite losing its endotoxic potencies such as the ability to induce NO and TNF production.
\end{abstract}

\section{Introduction}

Helicobacter pylori is recognised as a primary cause of active chronic gastritis and is reported to be associated with peptic ulcer disease $[1,2]$, low-grade B-cell gastric lymphoma of mucosa-associated lymphoid tissue and gastric adenocarcinoma [3,4]. Like the cell envelope of all other gram-negative bacteria, that of $H$. pylori contains lipopolysaccharide (LPS). In general, LPS is composed of a lipid core (lipid A) and polysaccharide side chains of variable length. Lipid A represents the endotoxic principle of active LPS. The carbohydrate portion consists of a core region that usually is genus- or species-specific and an outermost chain that is strain-specific and forms the basis of the O-antigenic classification [5]. LPS from members of the family Enterobacteriaceae has been demonstrated to be highly pro-inflammatory and LPS released from the infecting organisms causes various inflammatory symptoms and pathophysiological disorders, including fever, disseminated intravascular coagulation (DIC), multiple organ failure (MOF) and septic shock $[6,7]$.

Received 15 Jan. 2001; accepted 17 April 2001.

Corresponding author: Dr T. Kirikae (e-mail: tkirikae@ri. imcj.go.jp).
However, H. pylori LPS seems to lack strong endotoxicity $[5,8-11]$.

The most sensitive and rapid way to detect a trace amount of endotoxin/LPS or $(1 \rightarrow 3)-\beta$-D-glucan in solution or serum is to use the amoebocyte lysate of the horseshoe crab: the Limulus amoebocyte lysate $(\mathrm{LAL})$ test $[12,13]$. To avoid the action of $(1 \rightarrow 3)-\beta$-Dglucan-sensitive factor $\mathrm{G}$ in the LAL test [14-16], a highly sensitive and specific test for detecting endotoxin/LPS has been developed [17-21]. The improved LAL test is quite specific for LPS/lipid A and can detect picograms of endotoxin/LPS.

LAL coagulation activity of endotoxin/LPS has been thought to be closely correlated with its other biological activities, including pyrogenicity and macrophage $(\mathrm{M} \phi)$ activation. This study examined the biological activity of $H$. pylori LPS in comparison with its potency to coagulate LAL.

\section{Materials and methods}

\section{Reagents}

Four strains of H. pylori were used in this study: CG10 (isolated from a patient with chronic gastritis), GU2 
(isolated from a patient with gastric ulcer), DU8 (isolated from a patient with duodenal ulcer) and ATCC 43504. Each strain was grown on brain heart infusion agar plates supplemented with horse blood $10 \%$ at $37^{\circ} \mathrm{C}$ for 5 days under micro-aerophilic conditions (Gas Pack System without catalysis; BBL, Cockeysville, MD, USA) [22]. H. pylori LPS was extracted by the phenol-water method [23]. Briefly, phenol $90 \%$ was added to bacterial cells suspended in water and the mixture was heated at $65^{\circ} \mathrm{C}$ for $45 \mathrm{~min}$. After cooling, the aqueous phase was separated by centrifugation, dialysed and lyophilised to give crude extract. The extract was treated with DNAase and RNAase at $37^{\circ} \mathrm{C}$ overnight and then treated with proteinase $\mathrm{K}$ at $37^{\circ} \mathrm{C}$ for 1 day. After dialysis, LPS was separated by ultracentrifugation, washed twice and lyophilised. LPS from Escherichia coli O55 and O111:B4 was purchased from Sigma and Difco, respectively. Re chemotype LPS (ReLPS) from Salmonella minnesota R595 was a gift from Dr K. Hisatsune, Josai University, Sakado, Japan. Rhodobacter sphaeroides diphosphoryl lipid A (RsDPLA), which is known to be biologically inactive and a non-toxic LPS antagonist [24-29], was prepared from the LPS of $R$. sphaeroides ATCC 17023 as described previously [30]. Polymyxin B was purchased from Sigma.

\section{Mice}

C3H/HeN mice (Nippon Clea, Tokyo, Japan) were bred and maintained in the animal facility of the Jichi Medical School. Female mice were used at 10-15 weeks of age.

\section{Cell preparations}

Peritoneal $\mathrm{M} \phi$ were prepared from $\mathrm{C} 3 \mathrm{H} / \mathrm{HeN}$ mice according to the procedures described previously [31]. Briefly, murine peritoneal exudate cells (PEC) were isolated by peritoneal lavage 4 days after intraperitoneal injection of $1.5 \mathrm{ml}$ of thioglycolate broth $3 \%$. The PEC were plated at $2 \times 10^{5}$ cells/well in serumfree RPMI 1640 medium in 96-well plates (Nunc, Roskilde, Denmark), cultured for $2 \mathrm{~h}$ and then washed to remove non-adherent cells. The remaining cells were used as $\mathrm{M} \phi$. The viability of the cells was c. $99 \%$ as determined by trypan blue staining. TNF-sensitive L929 cells were provided by Dr M. J. Parmely, University of Kansas Medical Center and were grown at $37^{\circ} \mathrm{C}$ in air with $\mathrm{CO}_{2} 5 \%$ in RPMI 1640 medium containing heat-inactivated fetal bovine serum (FBS; JHR Bioscience, Lenexa, KS, USA) 5\%, $4 \mathrm{mM} \mathrm{L-}$ glutamine, penicillin $100 \mathrm{U} / \mathrm{ml}$ and streptomycin $100 \mu \mathrm{g} / \mathrm{ml}$.

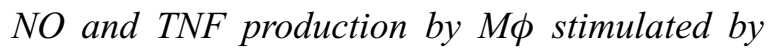 LPS}

$\mathrm{M} \phi$ were incubated in the presence or absence of various doses of LPS in RPMI with FBS $2 \%$ at $37^{\circ} \mathrm{C}$ in
$\mathrm{CO}_{2} 5 \%$. The supernates of the cultures were collected at $4 \mathrm{~h}$ for the TNF assay or at $48 \mathrm{~h}$ for the NO assay.

TNF activity was determined by a functional cytotoxic assay with the TNF-sensitive cell line L929, as described previously [32]. Briefly, L929 cells were plated in 96-well culture plates at $5 \times 10^{4}$ cells per well in $100 \mu$ l of RPMI 1640 medium with FBS 5\% and incubated for $20 \mathrm{~h}$. The cells were then cultured for an additional $18 \mathrm{~h}$ in the presence of serial dilutions of test supernate and actinomycin D (Sigma) $5 \mu \mathrm{g} / \mathrm{ml}$. The viability of the cells was determined by a quantitative colorimetric staining assay with a tetrazolium salt (3-[4,5-dimethylthiazol-2-yl]-2,5-diphenyltetrazolium bromide (MTT), Sigma). The absorbance at $540 \mathrm{~nm}\left(\mathrm{~A}_{540}\right)$ was read with a model Biomec 1000 Spectrophotometer (Beckman Instruments, Palo Alto, CA, USA.). TNF activity was expressed in units $/ \mathrm{ml}$, with $1 \mathrm{U}$ being the amount of TNF causing 50\% lysis of L929 cells.

NO formation was measured as its stable end product nitrite $\left(\mathrm{NO}_{2}{ }^{-}\right)$in culture supernates with the Griess reagent [33]. Briefly, $100 \mu \mathrm{l}$ of culture supernates was added to each well of 96-well plates and mixed with $100 \mu \mathrm{l}$ of Griess reagent (1:1 v/v; $N$-[1-naphthyl]ethylenediamine dihydrochloride $0.1 \%$ in water and sulphanilamide $1 \%$ in $\mathrm{H}_{3} \mathrm{PO}_{4} 5 \%$ ) and the $\mathrm{A}_{540}$ was read with a model Biomec 1000 spectrophotometer.

\section{LAL coagulation activity assay}

The LAL coagulation activity was assessed with the LPS-specific chromogenic test kit (Endospecy; Seikagaku, Japan) The Endospecy kit reagent consists of coagulation factors (factor C, factor B and pro-clotting enzyme from horseshoe crab, (Tachypleus tridentatus) and chromogenic substrate, $t$-butyloxycarbonyl-LeuGly-Arg- $p$-nitroanilide (Boc-Leu-Gly-Arg-pNA). LPS and RsDPLA were dissolved in pyrogen-free water and serial dilutions were made. The Endospecy kit reagent was added to each dilution and the $A_{540}$ was measured every $15 \mathrm{~s}$ with a Well Reader SK601 (Seikagaku). The LAL coagulation activity was expressed as a maximum value of $\mathrm{mAbsorbance} / \mathrm{min}$ in the assay. In the case of polymyxin B treatment, LPS samples were pre-incubated in the presence or absence of $15 \mu \mathrm{M}$ polymyxin $\mathrm{B}$ for $30 \mathrm{~min}$ before the LAL assay.

\section{Ex-vivo TNF production by human peripheral blood samples}

Peripheral whole blood was obtained with a heparinised syringe from a healthy volunteer (39-year-old male, negative $H$. pylori infection was determined by the urease test.). The blood was diluted five times in serum-free RPMI 1640 medium. The diluted samples ( $270 \mu \mathrm{l} /$ well) were pre-incubated in 96-well plates for $2 \mathrm{~h}$ at $37^{\circ} \mathrm{C}$ in $\mathrm{CO}_{2} 5 \%$ and then incubated in the presence of various doses of LPS at $37^{\circ} \mathrm{C}$ in $\mathrm{CO}_{2} 5 \%$ 
[31]. The supernates of the cultures were collected at $20 \mathrm{~h}$ after the incubation and stored at $-80^{\circ} \mathrm{C}$ until TNF levels of the supernates were assessed as described above.

\section{Results}

\section{LAL coagulation activity}

As shown in Fig. 1a, four preparations of $H$. pylori LPS showed high levels of LAL coagulation activity that were similar to those of E. coli and S. minnesota LPS. In contrast, the activity of RsDPLA was 100 times less than those of H. pylori, S. minnesota and $E$. coli LPS. However, RsDPLA did not inhibit the LAL activity of other LPS (data not shown). As polymyxin $B$ has been documented to neutralise many of the biological activities of LPS by binding to lipid A [34], the study examined whether the activities of $H$. pylori LPS were neutralised by polymyxin B. The LPS of $H$. pylori GU2 and DU8 and LPS of E. coli O55 were preincubated with $15 \mu \mathrm{M}$ polymyxin $\mathrm{B}$ at $37^{\circ} \mathrm{C}$ for $30 \mathrm{~min}$ and then their LAL coagulation activities were assessed. As shown in Fig. 1b, the activities of these $H$. pylori LPS preparations were not neutralised, although the activities were slightly decreased. In contrast, the
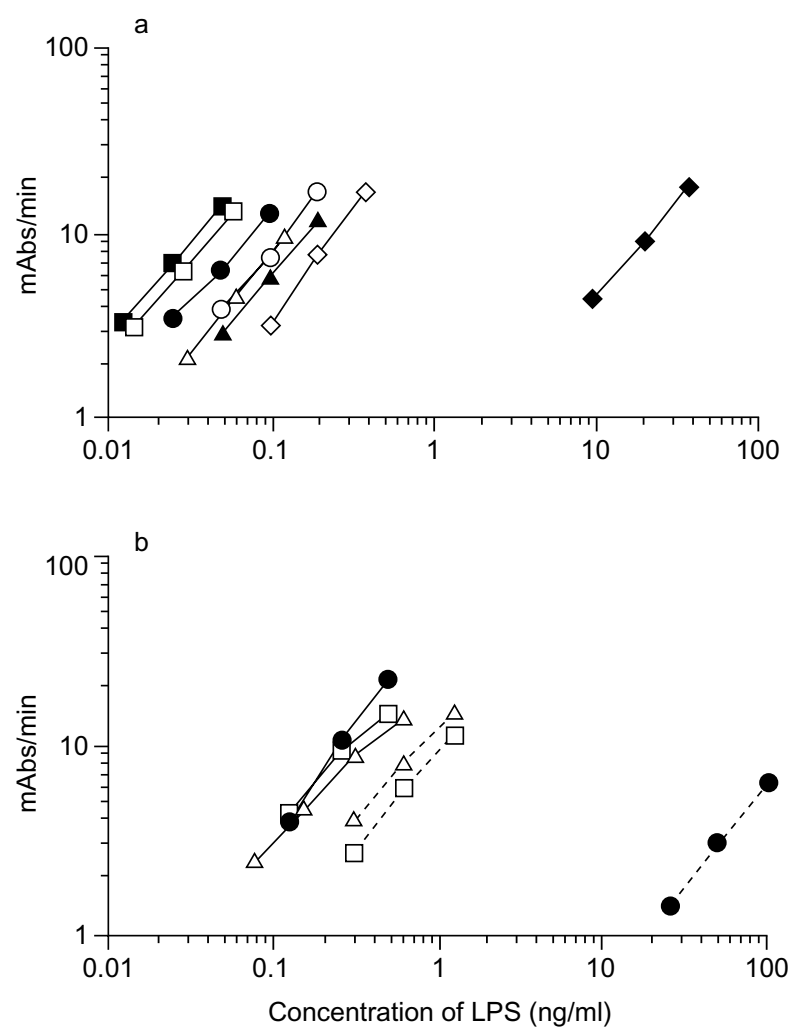

Fig. 1. LAL coagulation activities of LPS. (a) LPS of $H$.

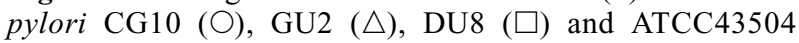
$(\diamond) ;$ E. coli $\mathrm{O} 55(\bullet)$ and O111;B4 $(\boldsymbol{\Delta})$; and S. minnesota R595 (ם) and RsDPLA ( $\bullet$ were analysed for their LAL coagulation activities. (b) LPS of $H$. pylori GU2 $(\triangle)$ and DU8 $(\square)$ and E. coli O55 (@) pre-incubated in the presence (---) or absence (-) of $15 \mu \mathrm{M}$ polymyxin $\mathrm{B}$ for $30 \mathrm{~min}$ were analysed for their LAL coagulation activities. activity of $E$. coli LPS was quite sensitive to polymyxin B treatment. These findings indicate that H. pylori LPS has enough potency to coagulate LAL, like other active LPS, but its potency is resistant to polymyxin $\mathrm{B}$. The slight reduction of LAL activity in the absence of polymyxin B may be caused by the adsorption of LPS to the wall of the vessel.

\section{TNF and NO production by murine peritoneal $M \phi$}

Next, the potency of the preparations for induction of TNF and NO by murine peritoneal $\mathrm{M} \phi$ in vitro was investigated. As shown in Fig. 2a, the addition of $S$. minnesota LPS $10 \mathrm{ng} / \mathrm{ml}$ induced nitrite production of c. $35 \mu \mathrm{M}$, whereas the same dose of $H$. pylori LPS produced no detectable nitrite. The addition of $H$. pylori ATCC43504 or GC10 LPS $1000 \mathrm{ng} / \mathrm{ml}$ barely induced the production of a $30 \mu \mathrm{M}$ level of nitrite. No H. pylori LPS, except that of ATCC 43504, possessed TNF-inducing activity (Fig. 2b). These findings in-
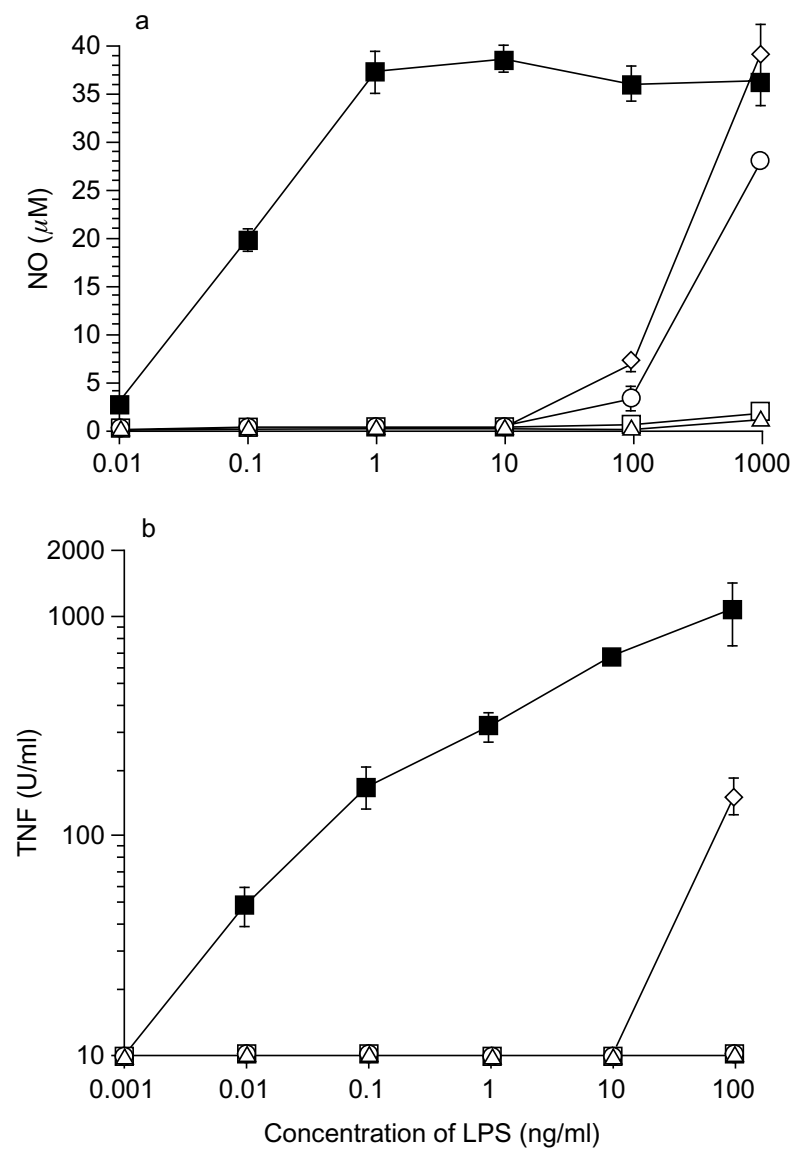

Fig. 2. Induction of TNF and NO production by murine peritoneal $\mathrm{M} \phi$ in response to LPS. Peritoneal exudate $\mathrm{M} \phi$ of $\mathrm{C} 3 \mathrm{H} / \mathrm{HeN}$ mice were cultured at $2 \times 10^{5}$ cells/well in serum-free RPMI 1640 medium in 96-well plates in the presence or absence of various doses of LPS at $37^{\circ} \mathrm{C}$ in $5 \% \mathrm{CO}_{2}$. The supernates of the cultures were collected at $4 \mathrm{~h}$ or $48 \mathrm{~h}$, and the levels of TNF and NO were assessed in the 4- and 48-h samples, respectively. LPS of $H$. pylori CG10 $(\bigcirc)$, GU2 $(\triangle)$, DU8 $(\square)$ and ATCC43504 $(\diamond)$ and of S. minnesota R595 (ם) were used for the assay. 
dicate that the endotoxic potency of $H$. pylori LPS to induce TNF and NO production by mouse $\mathrm{M} \phi$ is quite low when compared with the ability of $S$. minnesota LPS.

\section{TNF production by human peripheral whole blood}

H. pylori LPS only exhibited a low endotoxic activity as determined by its weak ability to induce TNF production by human peripheral whole blood cell cultures. As shown in Fig. 3, $1 \mathrm{ng}$ of $S$. minnesota $\mathrm{LPS} / \mathrm{ml}$ was enough to reach the plateau of TNF production, while $100 \mathrm{ng}$ of $H$. pylori LPS/ml hardly induced any TNF production. The production was barely seen when ATCC 43504 LPS, strain CG10 LPS or strain DU8 LPS $1000 \mathrm{ng} / \mathrm{ml}$ was added, but the same dose of strain GU2 LPS was not effective. These findings suggest that the ability of $H$. pylori LPS to induce TNF production by human peripheral monocytes is at least 1000 -fold lower than that of $S$. minnesota LPS.

\section{Discussion}

It was reported that endotoxic activities of $H$. pylori LPS, such as mitogenicity in mouse spleen cells, pyrogenicity in rabbits and toxic lethality in galactosamine-sensitised mice, were 500-1000-fold lower than those of Salmonella LPS [8] and that the production of NO, TNF and prostaglandin E2 (PGE2)

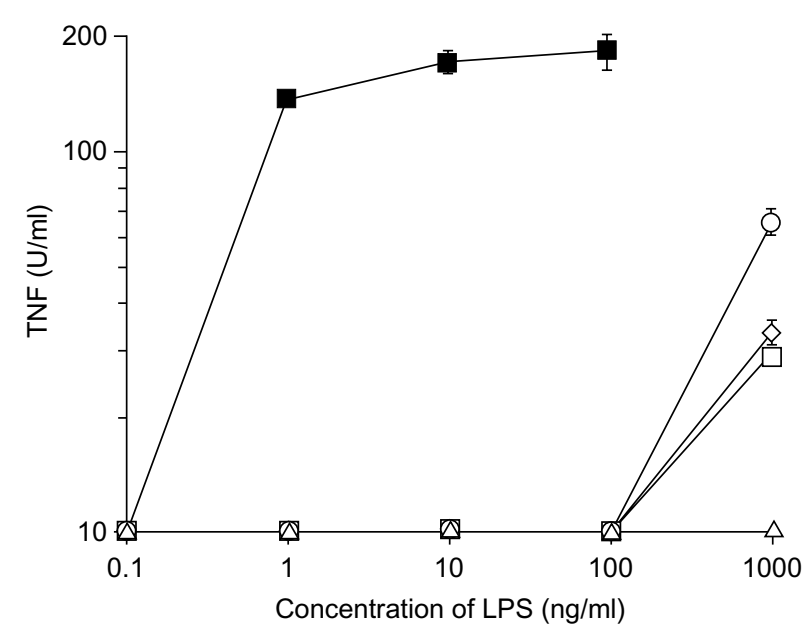

Fig. 3. Induction of TNF production by human whole peripheral blood in response to LPS. Human peripheral blood was obtained from a healthy male with a heparinised syringe and tube. The blood was diluted five-fold in RPMI 1640 medium and cultured in the presence of various doses of $H$. pylori LPS $(0.01-100 \mathrm{ng} / \mathrm{ml})$ or $S$. minnesota LPS $(0.3 \mathrm{ng} / \mathrm{ml})$, at $37^{\circ} \mathrm{C}$ in $5 \% \mathrm{CO}_{2}$ for $4 \mathrm{~h}$. At the end of culture, the blood samples were centrifuged (500 rpm for $3 \mathrm{~min}$ ) and the supernates were used for the TNF assay. LPS of $H$. pylori CG10 $(\bigcirc)$, GU2 $(\triangle)$, DU8 $(\square)$ and ATCC43504 $(\diamond)$ and of S. minnesota R595 (ם) were used for the assay. by murine or rat $\mathrm{M} \phi$ in response to $H$. pylori LPS was very low $[5,9-11]$. It was also reported that the production of TNF, interleukin(IL)-1 and IL-6 by human peripheral mononuclear blood cells [35] and TNF, PGE2 and NO by human leukaemia cells [9] in response to $H$. pylori LPS were all apparently lower than those in response to E. coli LPS. Furthermore, the oxidative metabolism and enzyme release from human neutrophils in response to various preparations of $H$. pylori LPS were 10 -fold lower than those induced by Salmonella LPS [36]. The findings in the present study that the biological activities of $H$. pylori LPS against murine $\mathrm{M} \phi$ and human monocytes were quite low coincided with the other reports described above, but the H. pylori LPS preparations in the former retained high LAL coagulation potency with resistance to polymyxin B treatment. To our knowledge, this is the first report of such an obvious dissociation of LAL coagulation potency from other biological activities of LPS. Mattsby-Baltzer et al. reported that lipid A prepared from $H$. pylori LPS with acetic acid hydrolysis showed low solubility and less LAL activity in comparison with lipid A of Campylobacter jejuni or $S$. typhimurium [37]. Lipid A of $H$. pylori is known to have a unique structure that contains uncommonly long 3-hydroxy fatty acids and the backbone consisting of a D-glucosamine disaccharide with a 2-aminoethylphosphate group at position $1 \quad[38,39]$. As neutral phospholipid is known to have no LAL activity [40], the neutral charge of lipid A moiety may be responsible for the low LAL activity of lipid A from $H$. pylori. Thus, removal of some structural moiety after acetic acid hydrolysis of $H$. pylori LPS, probably polysaccharide moiety, may affect its LAL coagulation potency: lipid $\mathrm{A}$ in combination with polysaccharide may activate the factor $\mathrm{C}$ enzyme. Moreover, polymyxin $\mathrm{B}$ did not interfere with the co-operative effect. As polymyxin $\mathrm{B}$ binds to negatively charged amphiphiles [41], polymyxin B may not interact with the lipid A moiety of $H$. pylori LPS. The structure of lipid A may be responsible for the polymyxin B resistance. Although endotoxic activity is not dependent on any single constituent of lipid A, a change in the lipid A structure can result in decreased endotoxic activity $[10,42]$. Many lipid A analogues have been chemically synthesised. It has been found that structural alteration of the analogues may lower some activity without affecting other activities [43-45]. Although structural information about the LPS/lipid A in $H$. pylori responsible for the full retention of LAL coagulation potency without cytokine-inducing activity is not available at present, some novel chemical structure may exist in the LPS. There is a need for studies to determine structure-activity relationships in LAL coagulation and mechanisms involved in the stimulation of the LAL coagulation cascade.

This work was supported in part by Grants-in-Aid for Science Research from the ministry of Education, Science and Culture of Japan (no.11670270 to T.K). 


\section{References}

1. Dunn BE, Cohen H, Blaser MJ. Helicobacter pylori. Clin Microbiol Rev 1997; 10: 720-741.

2. Kimura K, Ido K, Saifuku K et al. A 1-h topical therapy for the treatment of Helicobacter pylori infection. Am J Gastroenterol 1995; 90: 60-63.

3. Honda S, Fujioka T, Tokieda M, Satoh R, Nishizono A, Nasu M. Development of Helicobacter pylori-induced gastric carcinoma in Mongolian gerbils. Cancer Res 1998; 58: 4255-4259.

4. Watanabe $T$, Tada $M$, Nagai $H$, Sasaki $S$, Nakao $M$. Helicobacter pylori infection induces gastric cancer in Mongolian gerbils. Gastroenterology 1998; 115: 642-648.

5. Rietschel ET, Brade H. Bacterial endotoxins. Sci Am 1992; 267: 54-61.

6. Danner RL, Elin RJ, Hosseini JM, Wesley RA, Reilly JM, Parillo JE. Endotoxemia in human septic shock. Chest 1991; 99: $169-175$.

7. Morrison DC, Ryan JL. Endotoxins and disease mechanisms. Annu Rev Med 1987; 38: 417-432.

8. Muotiala A, Helandar IM, Pyhälä L, Kosunen TU, Moran AP. Low biological activity of Helicobacter pylori lipopolysaccharide. Infect Immun 1992; 60: 1714-1716.

9. Pérez-Pérez GI, Shepherd VL, Morrow JD, Blaser MJ. Activation of human THP-1 cells and rat bone marrow-derived macrophages by Helicobacter pylori lipopolysaccharide. Infect Immun 1995; 63: 1183-1187.

10. Rietschel ET, Kirikae T, Schade FU et al. Bacterial endotoxin: molecular relationships of structure to activity and function. FASEB J 1994; 8: 217-225.

11. Shapiro KB, Hotchkiss JH. Induction of nitric oxide synthesis in murine macrophages by Helicobacter pylori. Cancer Lett 1996; 102: 49-56.

12. Levin J, Bang F. Clottable protein in Limulus; its localization and kinetics of its coagulation by endotoxin. Thromb Diath Haemorrh 1968; 19: 186-197.

13. Nakano M. Detection method of LPS and its clinical applications: introduction. In: Okada K, Ogata H (eds) Shock: from molecular and cellular level to whole body. Proceedings of the Third International Shock Congress, Shock '95, Hamamatsu, Japan, 21-23 Oct. 1995. (Excerpta Medica International Congress Series no. 1102). Amsterdam, Elsevier. 1996: 81-84.

14. Kakinuma A, Asano T, Torii H, Sugino Y. Gelation of Limulus amoebocyte lysate by an antitumor $(1 \rightarrow 3)-\beta$-D-glucan. Biochem Biophys Res Commun 1981; 101: 434-439.

15. Ohki M, Nakamura T, Morita T, Iwanaga S. A new endotoxin sensitive factor associated with hemolymph coagulation system of horseshoe crab (Limulidae). FEBS Lett 1980; 120:217-220.

16. Tamura $H$, Obayashi $T$, Takagi $K$, Tanaka S, Nakahara $C$, Kawai T. Perchloric acid treatment of human blood for quantitative endotoxin assay using synthetic chromogenic substrate for horseshoe crab clotting enzyme. Thromb Res 1982; 27: 51-57.

17. Aketagawa J, Tanaka S, Tanaka H, Shibata Y, Saitô H. Activation of limulus coagulation factor $\mathrm{G}$ by several $(1 \rightarrow 3)-\beta$ D-glucans: comparison of the potency of glucans with identical degree of polymerization but different conformations. $J$ Biochem 1993; 113: 683-686.

18. Hu Z-Q, Asano K, Yamazaki T, Shimamura T. Effect of lipopolysaccharide on mouse mast cell indication by a splenic cell culture system. Infect Immun 1994; 62: 3844-3849.

19. Obayashi T, Kawai T, Tamura H, Nakahara C. New Limulus amoebocyte lysate test for endotoxaemia. Lancet 1982; 1: 289.

20. Obayashi T, Tamura H, Tanaka S et al. A new chromogenic endotoxin-specific assay using recombined Limulus coagulation enzymes and its clinical applications. Clin Chim Acta 1985; 149: $55-65$.

21. Tanaka S, Iwanaga S. Limulus test for detecting bacterial endotoxins. Methods Enzymol 1993; 223: 358-364.

22. Amano K, Hayashi S, Kubota T, Fujii N, Yokota S. Reactivity of Lewis antigen monoclonal antibodies with the lipopolysaccharides of Helicobacter pylori strains isolated from patients with gastroduodenal diseases in Japan. Clin Diagn Lab Immunol 1997; 4: 540-544.

23. Westphal O, Jann K. Bacterial lipopolysaccharides. Extraction with phenol-water and further application of the procedure. Methods Carbohydr Chem 1965; 5: 83-91.
24. Kirikae F, Kirikae T, Qureshi N, Takayama K, Morrison DC, Nakano M. CD14 is not involved in Rhodobacter sphaeroides diphosphoryl lipid A inhibition of tumor necrosis factor alpha and nitric oxide induction by taxol in murine macrophages. Infect Immun 1995; 63: 486-497.

25. Lynn WA, Golenbock DT. Lipopolysaccharide antagonists. Immunol Today 1992; 13: 271-276.

26. Qureshi N, Honovich JP, Hara H, Cotter RJ, Takayama K. Location of fatty acids in lipid A obtained from lipopolysaccharide of Rhodopseudomonas sphaeroides ATCC 17023. J Biol Chem 1988; 263: 5502-5504.

27. Qureshi N, Takayama K, Kurtz R. Diphosphoryl lipid A obtained from the nontoxic lipopolysaccharide of Rhodopseudomonas sphaeroides is an endotoxin antagonist in mice. Infect Immun 1991; 59: 441-444.

28. Salimath PV, Weckesser J, Strittmatter W, Mayer H. Structural studies on the non-toxic lipid A from Rhodopseudomonas sphaeroides ATCC 17023. Eur J Biochem 1983; 136:195-200.

29. Strittmatter W, Weckesser J, Salimath PV, Galanos C. Nontoxic lipopolysaccharide from Rhodopseudomonas sphaeroides ATCC 17023. J Bacteriol 1983; 155: 153-158.

30. Qureshi N, Takayama K, Meyers KC et al. Chemical reduction of 3-oxo and unsaturated groups in fatty acids of diphosphoryl lipid A from the lipopolysaccharide of Rhodopseudomonas sphaeroides. Comparison of biological properties before and after reduction. J Biol Chem 1991; 266: 6532-6538.

31. Kirikae T, Ojima I, Ma Z, Kirikae F, Hirai Y, Nakano M. Structural significance of the benzoyl group at the C-3-N position of paclitaxel for nitric oxide and tumor necrosis factor production by murine macrophages. Biochem Biophys Res Commun 1998; 245: 698-704.

32. Ruff MR, Gifford GE. Purification and physio-chemical characterization of rabbit tumor necrosis factor. J Immunol 1980; 125: $1671-1677$.

33. Green LC, Wagner DA, Glogowski J, Skipper PL, Wishnok JS, Tannenbaum SR. Analysis of nitrate, nitrite, and $\left[{ }^{15} \mathrm{~N}\right]$ nitrate in biological fluids. Anal Biochem 1982; 126: 131-138.

34. Morrison DC, Jacobs DM. Binding of polymyxin B to the lipid A portion of bacterial lipopolysaccharides. Immunochemistry 1976; 13: $813-818$

35. Birkholz S, Knipp U, Nietzki C, Adamek RJ, Opferkuch W. Immunological activity of lipopolysaccharides of Helicobacter pylori on human peripheral mononuclear blood cells in comparison to lipopolysaccharides of other intestinal bacteria. FEMS Immunol Med Microbiol 1993; 6: 317-324.

36. Nielsen H, Birkholz S, Andersen LP, Moran AP. Neutrophil activation by Helicobacter pylori lipopolysaccharides. J Infect Dis 1994; 170: 135-139.

37. Mattsby-Baltzer I, Mielniczuk Z, Larsson L, Lindgren K, Goodwin S. Lipid A in Helicobacter pylori. Infect Immun 1992; 60: 4383-4387.

38. Moran A. Cell surface characteristics of Helicobacter pylori. FEMS Immunol Med Microbiol 1995; 10: 271-280.

39. Suda Y, Ogawa T, Kashihara W et al. Chemical structure of lipid A from Helicobacter pylori strain 206-1 lipopolysaccharide. J Biochem 1997; 121: 1129-1133.

40. Muta $\mathrm{T}$, Tokunaga $\mathrm{F}$, Nakamura $\mathrm{T}$, Morita $\mathrm{T}$, Iwanaga $\mathrm{S}$. Limulus clotting factor C: lipopolysaccharide-sensitive serine protease zymogen. Methods Enzymol 1993; 223: 336-345.

41. Schröder G, Brandenburg K, Seydel U. Polymyxin B induces transient permeability fluctuations in asymmetric planar lipopolysaccharide/phospholipid bilayers. Biochemistry 1992; 31: $631-638$.

42. Rietschel ET, Brade L, Holst O et al. Molecular structure of bacterial endotoxin in relation to bioactivity. In: Nowotny A, Spitzer JJ, Ziegler EJ (eds) Cellular and molecular aspects of endotoxin reactions. Proceedings of the First Congress of the International Endotoxin Society (Endotoxin research series, vol. 1), San Diego, CA, 9-12 May 1990. (Excerpta Medica International Congress Series no. 923). Amsterdam, Elsevier. 1990: 15-32.

43. Homma JY, Matsuura M, Kumazawa Y. Studies on lipid A, the active center of endotoxin-structure-activity relationship. Drug Future 1989; 14: 645-665.

44. Kotani S, Takada H. Structural requirements of lipid A for endotoxicity and other biological activities. Adv Exp Med Biol 1990; 256: 13-43.

45. Takada H, Kotani S. Structural requirements of lipid A for endotoxicity and other biological activities. Crit Rev Microbiol 1998; 16: 477-523. 